\title{
Stability analysis of slurry trenches under surcharge in soft soils
}

\author{
Hongju Xiao ${ }^{1}$ a, Yuyong Sun ${ }^{1 b}$ \\ ${ }^{1}$ College of engineering and architecture Tongling University , Tongling Anhui 244000 \\ axiaohongju@126.com, bsunyuyong2@126.com
}

Keywords: Diaphragm wall; slurry trench; stability; surcharge

Abstract: The failure shape and approach for slurry trench stability analysis of diaphragm wall are studied by means of numerical simulation and theoretical analysis. From numerical simulation, the failure shape under surcharge in soft soil is approximate a pyramid for the slurry trench. Based on limit equilibrium theory, approach for stability analysis of slurry trench is derived.

\section{Introduction}

Diaphragm wall is one of the major retaining structures for deep excavations in soft soil. However, the collapse of deep slurry trench is often occurred during the construction due to the ground surcharge and unstable soil. The collapse of slurry trench not only inferiors the quality of construction, but also leads to excessive deformation of adjacent buildings and buried pipelines, even causing an engineering accident [1-3].

The centrifugal model tests conducted by Powrie and Kantartzi [4] proved that local failure is more probable with the ground overload. A 3-D numerical analysis discovered that the conspicuous sensibility of excavation stability to the elevation difference of the slurry surface and groundwater level [5]. The trench-stability theories can be classified into three types, namely the limit equilibrium method, finite element method and limit analysis based on plasticity limit theorems. The limit equilibrium methods are based on assumption of failure surfaces, as wedge, half-cylinder, slope- intercepted half cylinder, shell, or parabola [5-6]. Both soil movement and progressive failure can be estimated with finite element method [7-8]. The limit analysis has an advantage in that the lower-and upper-bound theorems bracket the true solution [9-10].

This paper focuses on the stability of the slurry trench in the construction of subsurface structural diaphragm wall in soft soil areas of Ningbo, China. To investigate the failure shape, a 3D finite element model with reduced shear strength is established. Based on the failure shape, an approach for stability analysis of slurry trench is derived using the limit equilibrium method.

\section{Numerical analysis of failure shape}

The influencing mechanism of surcharge on the stability of slurry trench, as well as the failure shape, is studied in this section. To achieve this, a 3-D slurry trench model is established using Plaxis 3D. The (2) 2-2 layer of Ningbo, China, is selected as uniform soil layer, which is a typical soft soil in this area. The soil is modelled as Mohr-Coulomb material considering the stress path of lateral unloading. The parameters of soil are shown in Table 1. The size of the slurry trench is $6-\mathrm{m}$ in length, $1-\mathrm{m}$ in thickness, and 46- $\mathrm{m}$ in depth. The size of " $\mathrm{T}$ " guide wall is $1-\mathrm{m}$ in width, $0.25-\mathrm{m}$ in thick and $1.5-\mathrm{m}$ in depth. The surcharge is mainly considered the weight of trenching machine, the common size of which is shown in Fig.1. The size of the trenching machine is that the outer distance between track shoes is $3.2-4.3 \mathrm{~m}$, width of track shoes is $0.8 \mathrm{~m}$, the overall crawler length is $5.68 \mathrm{~m}$ and the center line of grab to swing axis is $4.5-4.81 \mathrm{~m}$. The weight of 
trenching machine fully loaded is almost $85 \mathrm{t}$. To simplify calculation and considering the worst condition, the calculation diagram is shown in Fig.2. The surcharge is evenly distributed under the track shoes, $q=91.7 \mathrm{kPa}$. The model size is $25 \mathrm{~m} \times 25 \mathrm{~m} \times 60 \mathrm{~m}$. The reduced shear strength method is used to obtain the failure shape and the factor of safety $(F S)$.

Table 1 The parameters of soil

\begin{tabular}{|l|l|}
\hline Unit weight $\left(\gamma, \mathrm{kN} / \mathrm{m}^{3}\right)$ & 17 \\
\hline Cohesion $(c, \mathrm{kPa})$ & 14.6 \\
\hline Internal friction angle $\left(\varphi,^{\circ}\right)$ & 18 \\
\hline Dilation angle $\left(\psi,^{\circ}\right)$ & 0 \\
\hline Poisson's ratio $(v)$ & 0.2 \\
\hline Plastic straining due to primary deviatoric loading $\left(E_{50}^{r e f}, \mathrm{kPa}\right)$ & 10000 \\
\hline Plastic straining due to primary compression $\left(E_{\text {ocd }}^{r e f}, \mathrm{kPa}\right)$ & 15000 \\
\hline Elastic unloading/reloading $\quad\left(E_{u r}^{r e f}, \mathrm{kPa}\right)$ & 30000 \\
\hline Stress dependent stiffness according to a power law $(\mathrm{m})$ & 0.8 \\
\hline
\end{tabular}
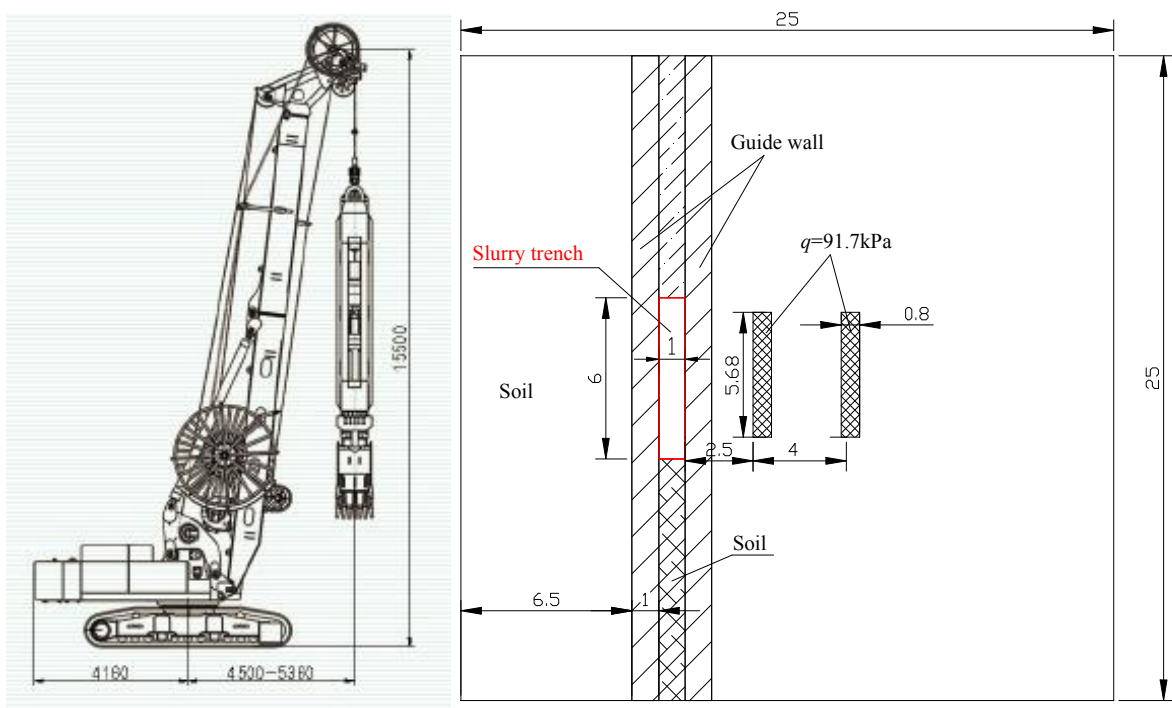

(a)

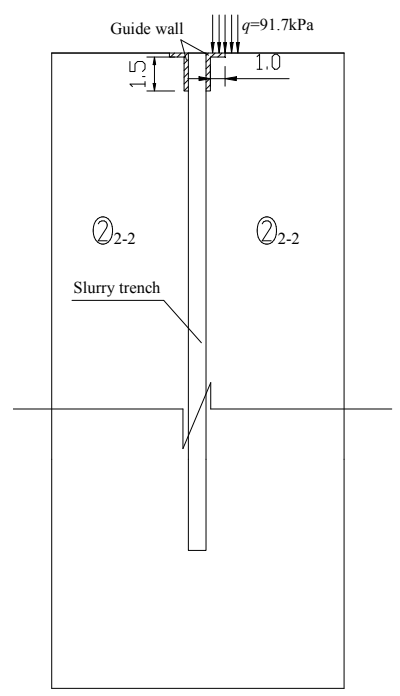

(b)

Fig.1 The common size of a trenching machine

Fig.2 Schematic diagram of the model: (a) plan view; (b) side view

According to the simulation, the failure shape is presented in Fig.3. It is shown that the deformation of slurry trench, which is caused by the weight of construction facilities on the ground, is mainly concentrated on the shallow $10 \mathrm{~m}$ soil. The failure zone is approximately a triangle along the depth direction, while the appearance on the ground is a triangular deformation from the overloading position to the edge of the slurry wall, as is shown in Fig. 3(b).

\section{Approach for stability analysis}

From the numerical simulation results, the failure shape of slurry trench occurs in the shallow layer with ground surcharge. The failure shape resembles a triangle in both the profile view and the plan view. This failure shape can be simplified to be the model shown in Fig.4. 
(1) Basic assumptions

For simplicity, the failure shape is assumed to be the pyramid ABCDE, and the shear failure happens on the bottom surface ADE.

(1) The failure surface has no deformation nor displacement in the initial condition;

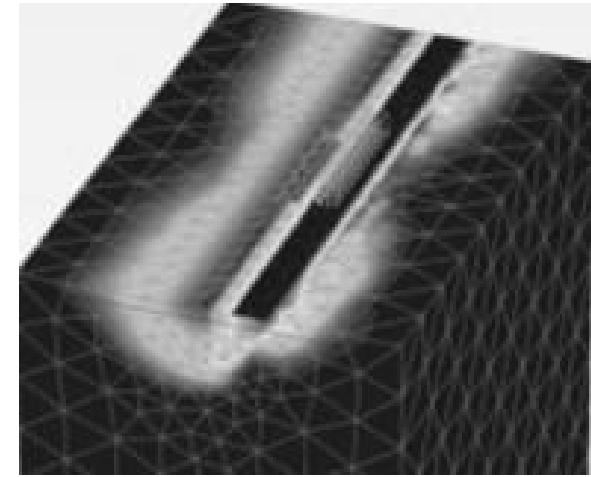

(a) 3D failure shape

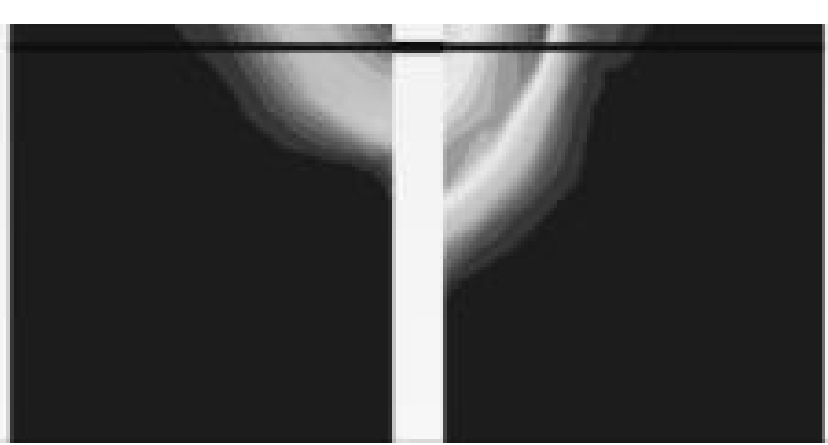

(b) failure shape at the central section of slurry trench

Fig.3 Failure shapes of slurry trench with surcharges
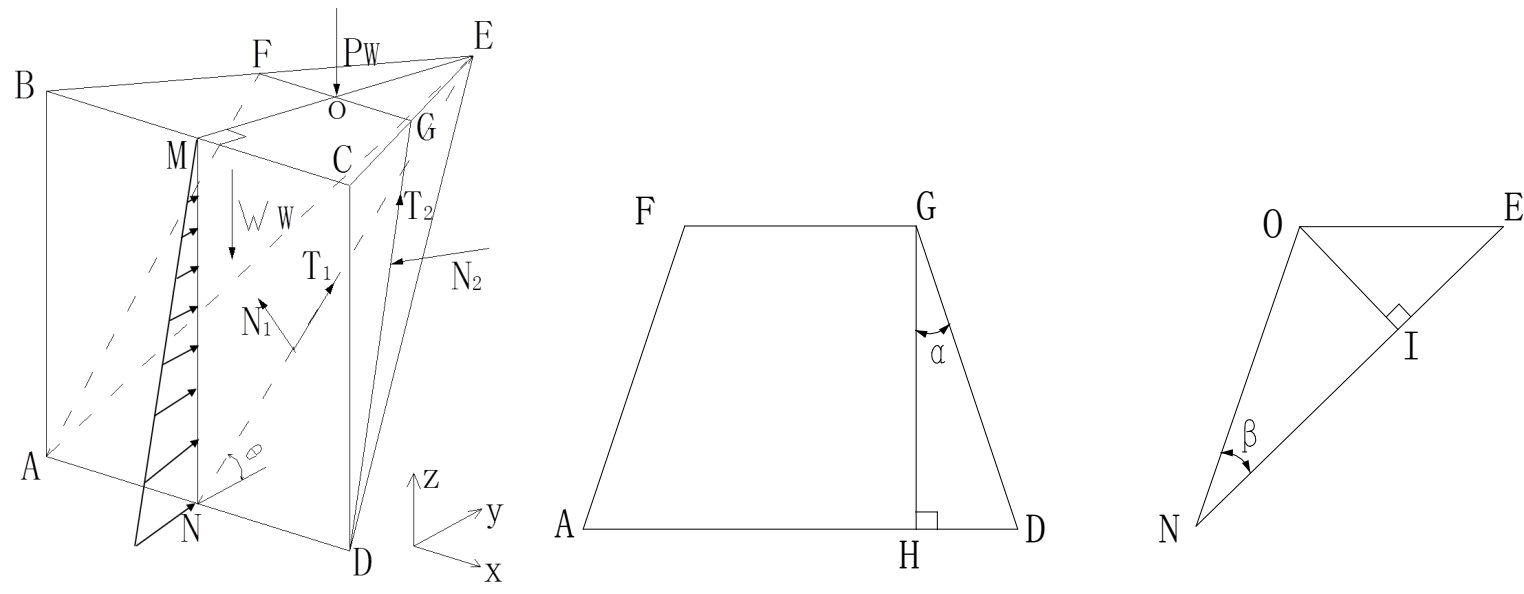

Fig.4 Simplified global failure shape

(2) The global failure shape is horizontally symmetric;

(3) Under ultimate state, both sides $\mathrm{ABE}$ and $\mathrm{CDE}$ are under the force of static earth pressure, bottom surface $\mathrm{ADE}$ is under the force of active earth pressure, the shear failure obeys the criteria of Mohr-Coulumb;

(4) The sliding track of the failure surface is line AF and DG and point F and G are the midpoints of line $\mathrm{BE}$ and line $\mathrm{CE}$;

(5) The inclination angle of the surface ADE, $\theta$, equals to the angle of failure surface in active Rankine earth pressure, as $\theta=45^{\circ}+\phi / 2$.

(G) The surcharge acts on the centroid of triangle $\mathrm{BCE}$, which means $\mathrm{ME}=2 \mathrm{MO}$, where $\mathrm{MO}$ is the horizontal distance (s) of the overload to the edge of slurry wall;

(7) Slurry pressure is assumed as static water pressure and the slurry level is at $0.5 \mathrm{~m}$ below the ground surface.

(2) Approach for stability analysis 
From these assumptions, the approach for slurry trench stability analysis can be derived as follows.

The normal pressure on the bottom surface is:

$$
N_{1}=\int_{0}^{b} K_{a} \gamma z \frac{z}{b} a d z=\frac{1}{3} K_{a} \gamma a b^{2}
$$

The area of the bottom surface, triangle ADE, is:

$$
A_{1}=a b /(2 \sin \theta)
$$

The shear force on the bottom is:

$T_{1}=c A_{1}+N_{1} \tan \phi$

Substituting Eq. (1) and (2) into Eq. (3), the shear force on the bottom surface, $\mathrm{T}_{1}$, is obtained:

$$
T_{1}=\frac{a b c}{2 \sin \theta}+\frac{K_{a} \gamma a b^{2}}{3} \tan \phi
$$

The normal pressure on the lateral surface is:

$$
N_{2}=\int_{0}^{b} K_{0} \gamma z \frac{(b-z) \sqrt{\left(\frac{a}{2}\right)^{2}+\left[b \tan \left(\frac{\pi}{2}-\theta\right)\right]^{2}}}{b} d z=\frac{K_{0} \gamma b^{2} \sqrt{\left(\frac{a}{2}\right)^{2}+\left[b \tan \left(\frac{\pi}{2}-\theta\right)\right]^{2}}}{6}
$$

The area of the lateral surface, which is the triangle CDE, is calculated as:

$$
A_{2}=\frac{1}{2} b \sqrt{\left(\frac{a}{2}\right)^{2}+\left[b \tan \left(\frac{\pi}{2}-\theta\right)\right]^{2}}
$$

The shear force on the lateral surface is:

$T_{2}=c A_{2}+N_{2} \tan \phi$

Substituting Eq.(5) and (6) into Eq. (7), the shear force on the lateral surface, $\mathrm{T}_{2}$, is expressed in Eq. (8).

$$
T_{2}=\frac{1}{2} b c \sqrt{\left(\frac{a}{2}\right)^{2}+\left[b \tan \left(\frac{\pi}{2}-\theta\right)\right]^{2}}+\frac{K_{0} \gamma b^{2} \sqrt{\left(\frac{a}{2}\right)^{2}+\left[b \tan \left(\frac{\pi}{2}-\theta\right)\right]^{2}}}{6} \tan \phi
$$

The pressure component of the slurry along the failure surface can be written in the function below:

$$
T_{3}=\frac{1}{2} \gamma_{\mathrm{s}} a(b-0.5)^{2} \cos \theta
$$

Thus, the $F S$ of the slurry trench stability is expressed as the equation below.

$$
K=\frac{T_{1}+2 T_{2} \cos \alpha \cos \beta+T_{3}}{(W+P) \cos \left(\frac{\pi}{2}-\theta\right)}
$$

Substituting Eq.(4), (8), and (9) into Eq. (10), the FS function of slurry trench stability is derived as Eq. (11).

$$
K=\frac{1}{(W+P) \cos \left(\frac{\pi}{2}-\theta\right)}\left\{\frac{a b c}{2 \sin \theta}+\frac{K_{a} \gamma a b^{2}}{3} \tan \phi+\frac{1}{2} \gamma_{\mathrm{s}} a(b-0.5)^{2} \cos \theta+\right.
$$




$$
\left.\left[b c \sqrt{\left(\frac{a}{2}\right)^{2}+\left[b \tan \left(\frac{\pi}{2}-\theta\right)\right]^{2}}+\frac{K_{0} \gamma b^{3} \sqrt{\left(\frac{a}{2}\right)^{2}+\left[b \tan \left(\frac{\pi}{2}-\theta\right)\right]^{2}}}{3}\right] \tan \phi \cos \alpha \cos \beta\right\}
$$

In which: $\alpha=\arctan \left\{\frac{a}{b \sqrt{4+\tan ^{2}\left(\frac{\pi}{2}-\theta\right)}}\right\} \quad \beta=\arctan \left(\frac{\sin \left(\frac{\pi}{2}-\theta\right)}{\sqrt{4+\left[\tan \left(\frac{\pi}{2}-\theta\right)\right]^{2}}}\right)$

Where: $a$ is the length of single diaphragm wall $A D ; b$ is the depth of failure mass $A B, b=2 s / \tan \theta$, where $\mathrm{s}$ is the horizontal distance of the overload to the edge of slurry trench; $K_{0}$ is the coefficient of static earth pressure, and $K_{a}$ is the coefficient of the active earth pressure; $\gamma$ is the unit weight of soil, $\mathrm{kN} / \mathrm{m}^{3} ; c$ is the cohesion of the soil, $\mathrm{kPa} ; \phi$ is the degree of friction angle of the soil; $\gamma_{\mathrm{s}}$ is the unit weight of the slurry, $\mathrm{kN} / \mathrm{m}^{3} ; A_{1}$ is the area of the bottom surface, $\mathrm{m}^{2}$, and $A_{2}$ is the area of the lateral surface, $\mathrm{m}^{2} ; w$ is the gravity on the failure mass in $\mathrm{kN} ; P$ is surcharge, $\mathrm{kN}$; and $K$ is the factor of safety on the slurry trench stability.

According to the Chinese Code GB50030-2002 [11], as the Technical code for building slope engineering, this factor of safety for first grade slopes should not be smaller than 1.30. When $F S K \geq 1.30$, the slurry trench is in a stable state. Contrarily, when $\mathrm{K}<1.30$, the failure of slurry trench may be occurred.

\section{Conclusions}

The following conclusions can be drawn: (1) The failure zone for the slurry trench of a diaphragm wall in soft soil under overloading is approximatively a pyramid; (2) The criterion for pyramid instability is derived using limit equilibrium theory.

\section{Acknowledgements}

The financial support received from the Anhui Provincial Outstanding Young Talents Domestic Visiting Scholar Plan (No. gxfx2017114) is gratefully acknowledged.

\section{References}

[1] Farmer I W, Attewell P B. "Ground movements caused by a bentonite-supported excavation in London clay". Geotechnique, 23(4):577-581, 1973.

[2] Lings M L, Nash D F T, Ng C W W, Boyce M D. "Observed behaviour of a deep excavation in Gault clay: A preliminary appraisal". Proceedings of 10th European Conference on Soil Mechanics and Foundation Engineering. Netherlands, 467-470, 1991.

[3] Liu Guobin, Lu Hanxin. "Study on the influence of upon building settlement diaphragm wall trench construction". Chinese Journal of Geotechnical Engineering, 26(2), 287-289, 2004.(Chinese)

[4] Powrie W, Kantartzi C. "Ground response during diaphragm wall installation in clay : centrifuge model test”. Geotechnique, 46(4), 725-739, 1996.

[5] Tsai J. S, Jou L. D and Hsieh H. S. "A full-scale stability experiment on a diaphragm wall trench”. Canadian Geotechnical Journal, 37, 379-392, 2000. 
[6] Fox P J. "Analytical solutions for stability of slurry trench". J. Geotech. Geoenviron. Eng., 130(7), 749-758, 2004.

[7] Srivastava, A., Babu, G., and Haldar. "Influence of spatial variability of permeability property on steady state seepage flow and slope stability analysis". Engineering Geology, 110, 93-101, 2010.

[8] Stolle D., and Guo P. Limit equilibrium slope stability analysis using rigid finite elements. Canadian Geotechnical Journal, 45(5), 653-662, 2008.

[9] Kumar, J., Sahoo, J. P. "Upper bound solution for pullout capacity of vertical anchors in sand using finite elements and limit analysis". International Journal of Geomechanics, 12(3), 333-337, 2012.

[10]Li, A. J., Merifield, R. S., and Lyamin, A. V. "Three-dimensional stability charts for slopes based on limit analysis methods". Canadian Geotechnical Journal, 47(12), 1316-1334, 2010.

[11]Professional Standards Compilation Group (PSCG). Technical code for building slope engineering. Beijing, China, 2002.(Chinese)

[12] Xu Yonggang. Effects of traffic and construction overload on the deformation and stability of slurry wall of diaphragm. Tongji University, 2015.(Chinese) 